\title{
Treatment Mode Preferences in Rheumatoid Arthritis: Moving Toward Shared Decision-Making
}

This article was published in the following Dove Press journal:

Patient Preference and Adherence

\author{
Peter C Taylor (iD) \\ Neil Betteridge ${ }^{2}$ \\ T Michelle Brown ${ }^{3}$ \\ John Woolcott ${ }^{4}$ \\ Alan J Kivitz ${ }^{5}$ \\ Cristiano Zerbini ${ }^{6}$ \\ Diane Whalley ${ }^{7}$ \\ Oyebimpe Olayinka-Amao ${ }^{3}$ \\ Connie $\mathrm{Chen}^{8}$ \\ Palle Dahl ${ }^{9}$ \\ Dario Ponce de Leon ${ }^{10}$ \\ David Gruben (ID) 1 \\ Lara Fallon ${ }^{12}$ \\ 'Botnar Research Centre, University of \\ Oxford, Oxford, UK; ${ }^{2}$ Neil Betteridge \\ Associates, London, UK; ${ }^{3}$ Patient-Centered \\ Outcomes Assessment Group, RTI Health \\ Solutions, Research Triangle Park, NC, USA; \\ ${ }^{4}$ Patient and Health Impact, Health \\ Economics and Outcomes Research, Pfizer \\ Inc, Collegeville, PA, USA; ${ }^{5}$ Altoona Center \\ for Clinical Research, Duncansville, PA, USA; \\ ${ }^{6}$ Department of Rheumatology, Centro \\ Paulista De Investigação Clinica, São Paulo, \\ Brazil; ${ }^{7}$ Patient-Centered Outcomes \\ Assessment Group, RTI Health Solutions, \\ Manchester, UK; ${ }^{8}$ Xeljanz, Rheumatology, \\ Inflammation \& Immunology Medical Affairs, \\ Pfizer Inc, New York, NY, USA; ' Medical \\ Affairs, International Developed Markets, \\ Inflammation \& Immunology, Pfizer Inc, \\ Ballerup, Denmark; ${ }^{10}$ Medical Affairs Latin- \\ America, Pfizer Inc, New York, NY, USA; \\ "Statistical Research and Data Science \\ Center, Pfizer Inc, Groton, CT, USA; \\ ${ }^{12}$ Global Medical Affairs, Pfizer Inc, \\ Montreal, QC, Canada
}

Correspondence: Peter C Taylor

Botnar Research Centre, University of

Oxford, Windmill Road, Headington,

Oxford OX3 7LD, UK

Tel +44I865227323

Email peter.taylor@kennedy.ox.ac.uk
Purpose: Current knowledge of the reasons for patients' preference for rheumatoid arthritis (RA) treatment modes is limited. This study was designed to identify preferences for four treatment modes, and to obtain in-depth information on the reasons for these preferences.

Patients and Methods: In this multi-national, cross-sectional, qualitative study, in-depth interviews were conducted with adult patients with RA in the United States, France, Germany, Italy, Spain, Switzerland, the United Kingdom, and Brazil. Patients' strength of preference was evaluated using a 100-point allocation task $(0-100 ; 100=$ strongest $)$ across four treatment modes: oral, self-injection, clinic-injection, and infusion. Qualitative descriptive analysis methods were used to identify, characterize, and summarize patterns found in the interview data relating to reasons for these preferences.

Results: 100 patients were interviewed (female, 75.0\%; mean age, 53.9 years; mean 11.6 years since diagnosis). Among the four treatment modes, oral administration was allocated the highest mean (standard deviation) preference points (47.3 [33.1]) and was ranked first choice by the greatest percentage of patients $(57.0 \%)$, followed by selfinjection (29.7 [27.7]; 29.0\%), infusion (15.4 [24.6]; 16.0\%), and clinic-injection (7.5 [14.1]; 2.0\%). Overall, $56.0 \%$ of patients had a "strong" first-choice preference (ie, point allocation $\geq 70)$; most of these patients chose oral $(62.5 \%)$ vs self-injection (23.2\%), infusion $(10.7 \%)$, or clinic-injection $(3.6 \%)$. Speed and/or ease of administration were the most commonly reported reasons for patients choosing oral $(52.6 \%)$ or self-injection $(55.2 \%)$. The most common reasons for patients not choosing oral or self-injection were not wanting to take another pill $(37.2 \%)$ and avoiding pain due to needles $(46.5 \%)$, respectively.

Conclusion: These data report factors important to patients regarding preferences for RA treatment modes. Patients may benefit from discussions with their healthcare professionals and/ or patient support groups, regarding RA treatment modes, to facilitate shared decision-making.

Keywords: drug administration, patient perspective, qualitative research, surveys

\section{Plain Language Summary}

Treatments for rheumatoid arthritis (RA) can vary in how they are taken (types of administration). When making treatment decisions, the patient's opinion is crucial. Little is known about why patients with RA prefer some types of administration over others.

In this study, patients with RA were interviewed about their preferences for types of RA treatment administration. The treatment types discussed were: by mouth (oral administration), by injection (self-injection or clinic-injection), and by drip (infusion).

Most patients' top choice was oral administration, followed by self-injection, infusion, and then clinic-injection. Patients often preferred the speed and ease of oral treatments. Others wanted to avoid taking more pills, or were worried about forgetting to take a pill every day. 
The speed of self-injection was a common reason for preferring this treatment type. Patients who preferred to avoid selfinjection often wanted to avoid pain from needles.

Reasons for preferring infusion included that it did not need to be administered very often. Patients who preferred to avoid infusion often felt that it was inconvenient.

Almost all patients preferred not to have clinic-injections, most often because of their inconvenience. The few patients who did prefer this treatment type felt that it worked better/faster and they felt safer and more comfortable with an expert administering their treatment.

The results of this study provide detailed information about the reasons why patients might prefer one RA treatment over another. This information highlights the importance of individual patient perceptions of treatments, and could help physicians in making shared decisions with patients.

\section{Introduction}

Rheumatoid arthritis (RA) is a progressive autoimmune disease, with various environmental and genetic factors implicated in its etiology. ${ }^{1-3}$ RA primarily targets synovial tissue, cartilage, and bone. ${ }^{1,3}$ The disease is characterized by pain, swelling, and destruction of joints, with resultant disability and decrements to patients' quality of life, eg, through: pain; frequent and/or extreme fatigue; difficulty carrying out basic daily activities; depression and/or anxiety. $1,2,4$

Several types of treatments are available for RA: nonsteroidal anti-inflammatory drugs (for symptomatic relief); corticosteroids; immunosuppressants; conventional synthetic disease-modifying antirheumatic drugs (csDMARDs); and advanced therapies, including biologic DMARDs (bDMARDs) and targeted synthetic DMARDs (tsDMARDs). Currently, csDMARDs - most commonly methotrexate (MTX) - are used in the early treatment of RA and can be administered as monotherapy or in combination with bDMARDs or tsDMARDs; bDMARDs, particularly tumor necrosis factor inhibitors, and tsDMARDs are recommended for use in patients with an inadequate response to at least one csDMARD. ${ }^{5,6}$ csDMARDs are mostly administered orally; however, MTX can also be administered by subcutaneous injection. ${ }^{7}$ bDMARDs require administration by intravenous infusion or subcutaneous injection. ${ }^{8}$ tsDMARDs include the oral Janus kinase inhibitors tofacitinib and baricitinib. ${ }^{6}$

Treatment guidelines provide a framework to inform management decisions, and emphasize the importance of shared decision-making between patients and their healthcare professionals. ${ }^{5}$ Physicians and patients may place a different emphasis on the key goals of RA management. While physicians aim for their patients to achieve clinical remission or low disease activity, ${ }^{5,6}$ this may contrast with the priorities of patients; eg, in an international survey, patients most commonly defined successful treatment as a reduction of pain and/or swelling/inflammation of joints, and improvements in quality of life. ${ }^{9}$ Of survey respondents who were under the care of a healthcare professional, almost half agreed that dialogue with their healthcare professional would optimize management of their RA, yet $62 \%$ of the patients surveyed said that they felt uncomfortable raising treatment or disease concerns with their healthcare professional. ${ }^{9}$

The patient viewpoint is crucial in a shared decisionmaking model. Although patients with RA value aspects related to medication efficacy and safety, ${ }^{10,11}$ route of administration may be an important medication attribute relevant for patients' preference among available RA therapies. $^{10,12-17}$ This has been demonstrated in a discretechoice experiment completed by patients with RA in Germany, which indicated that an oral mode was most desired and intravenous infusion was most rejected. ${ }^{17}$

Published research to explore patients' perspectives on the available RA treatment options and their attributes in an in-depth, qualitative manner is limited. Moreover, little is known about differences in preferences associated with country, culture, or lifestyle - factors facing clinicians who must make considerations while providing individualized care for patients with RA. ${ }^{18}$ The importance of this is highlighted by several studies reporting that there are racial and ethnic disparities in the disease status of patients with RA. ${ }^{19-23}$ Given that, even within the same country, physicians are likely to see patients from a range of cultural heritages, informed and appropriate dialogue between patients and physicians is key. ${ }^{18}$

As the treatment landscape for RA evolves, understanding patients' knowledge, beliefs, and perceptions about modes of administration can inform and improve patient-physician collaboration in making treatment decisions, and can identify patient education needs regarding RA treatments and modes of administration.

This study was designed to evaluate patient preferences for RA treatment modes and reasons for these preferences through qualitative research. Specific objectives were to provide insight into the administration modes preferred by patients with RA, explore the perceptions, beliefs, and 
attitudes associated with these preferences, and identify potential patient characteristics associated with these preferences.

\section{Patients and Methods}

This multi-national, cross-sectional, qualitative study involved the conduct of in-person interviews with a sample of 100 patients who reported a previous physician diagnosis of RA in the United States (US), Europe (France, Germany, Italy, Spain, Switzerland, and the United Kingdom [UK]), and Brazil. This study was performed under a research contract between RTI Health Solutions and Pfizer Inc, and was funded by Pfizer Inc. All patients provided written informed consent, and the RTI International Institutional Review Board reviewed the study on ethical grounds in the US. In the European countries and Brazil, the study was exempt from ethics committee review in accordance with national criteria: the surveys were non-interventional and were not conducted as a clinical study.

Patients were recruited from the community by telephone by medical recruiting companies. These companies (one in the US and one in Europe) maintain large databases of individuals who live in the local area and have agreed to be contacted for participation in research studies. Potential participants were identified based on their current or past report of health conditions and/or treatment experience, and their eligibility was identified using a recruitment screener for the specific study criteria. Eligible patients were adults ( $\geq 18$ years of age) with selfreport of a physician diagnosis of RA, and taking a csDMARD, bDMARD, or tsDMARD. Patients with certain rheumatological comorbidities (fibromyalgia, lupus, or Sjögren's syndrome) were excluded, as the presence of these conditions may impact the patients' treatment preferences. Demographic characteristics and RA treatment information were obtained at screening.

Due to the qualitative and descriptive nature of the study (that is, no hypothesis testing was performed), it was not applicable to base sample size on a power calculation. However, to support the research questions, the total sample size $(\mathrm{N}=100)$ and sample plan were determined to allow select subgroup and country comparisons. Patient quotas by country were 30 patients from the US, and 10 patients each from France, Germany, Italy, Spain, Switzerland, the UK, and Brazil. To ensure a representative RA sample and facilitate analysis by country and/or sociodemographic factors, sub-quotas were established for patients in each country: female (70-80\%); <55 years of age (40-60\%); current or recent use (past 2 years) of a bDMARD for RA (45-66\%); RA bDMARD-naïve (35-55\%); current or recent use (past 2 years) of tofacitinib (the US only, 10-15\%).

To ensure consistency in topics discussed, the interviews followed a semi-structured guide and were conducted in the native language of the country with translated materials (translation was performed by native speakers at AplusA). All interviews were conducted in person. In the US and the UK, interviews were conducted by experienced interviewers from RTI. Elsewhere in Europe and in Brazil, interviews were conducted by experienced, approved RTI subcontractor, AplusA. RTI provided training and ensured standardization of the interview process. The interviewers had no previous/personal knowledge of the patients. Interviews in the US were conducted at a central research facility and, as customary in Europe and Brazil, they were conducted in the patient's home. Each patient was interviewed once for up to $1 \mathrm{hr}$, and the interviews were audio-recorded. The interviews included discussion of patient preferences for treatment modes of administration, as well as discussion on: patients' general experiences with RA; current and past treatments, including administration modes; current RA symptoms, including pain and fatigue (0-10 scale, where 0 represented no pain or fatigue and 10 represented the worst possible pain or fatigue, in the past 7 days), and severity of RA (mild, moderate, severe, or very severe); current satisfaction with treatment (0-10 satisfaction scale, where 10 indicated greater satisfaction). Patients were further asked to describe their current RA symptoms and how their symptoms had changed since the time they were first diagnosed.

The topic of RA treatment mode preference included an exercise in which the patient assessed four treatment modes: oral (once daily) administration; self-injection (weekly); clinic-injection (weekly); and infusion (monthly). For each treatment mode, the patient ranked the mode $(0-100$ points allocated across modes, where more points represented stronger preferences), from which a strength of preference was determined. "Strong" preferences reflected a point allocation of at least the median number of points allocated across the first-ranked mode. After providing their preference points for the four modes, reasons for preference and point allocation were discussed. Where relevant, certain patients were asked about the impact, if any, of several factors on their expressed mode preferences: increasing 
oral mode to twice daily rather than once daily; adding a second drug to their oral treatment; and decreasing selfinjection to every 2 weeks rather than every week. Similarly, where applicable, patients were asked about their overall perceptions of MTX and bDMARDs. As treatment mode scenarios were only posed to a proportion of the interviewed patients (for whom the scenarios were relevant), a qualitative reporting scheme was used (eg, some patients, around half of patients).

All data, including de-identified interview transcripts, were translated (by native speakers at AplusA) and reviewed in English. Qualitative analysis of the transcripts and interviewers' field notes was conducted by RTI Health Solutions using ATLAS.ti software (v7.5). Qualitative descriptive analysis methods were used to identify, characterize, and summarize patterns found in the interview data, and a series of thematic codes was created to identify dominant concepts across the interviews. ${ }^{24}$ Patient feedback related to treatment mode preferences, experiences, beliefs, likes, and dislikes was coded by two coders so that concepts could be identified and compared across interviews. Example coding trees for administration mode likes and dislikes are presented in Figure S1. To ensure accuracy and consistency in the coding of the qualitative transcript data, the first 10 transcripts were double coded, meaning that two different people coded these transcripts. Any discrepancies found between these codes were resolved by the two coders and in discussion with Dr TM Brown. A random selection of approximately $10 \%$ of the remaining transcripts was double coded for additional quality control. Descriptive analyses were used to summarize the sociodemographic, lifestyle, and clinical data provided by patients at screening and during the interview. Quantitative analyses of the preference point and ranking outcome variables were conducted using SAS for Windows Version 9.4. ${ }^{25}$

The following variables were split into subgroups for the purpose of exploring any significant differences in treatment mode preferences that may be associated with these characteristics: sex; age; education level; employment status; race/ethnicity; relationship status; life stage; income level; comorbid health conditions; number of medications; smoking status; alcohol consumption; exercise habits; years since diagnosis; RA pain, fatigue, and overall severity; and current RA treatments. Thresholds used for variable subgroups were based on meaning, distribution, and sample size, as applicable, to support meaningful analysis and interpretation.
The design of this study was not intended for statistical comparisons. However, t-tests of differences in means, and z-scores in differences of rates, were conducted for select sample characteristics, outcome variables, and subgroup comparisons. The z-scores used the normal approximation to the binomial, and both t-tests and z-scores were applied in pairwise testing between two independent samples. $P$ values were considered to be descriptive, and $p$ values $<0.05$ are noted for the reader; as there was no hypothesis testing, there were no adjustments for multiple comparisons in the $\mathrm{p}$ values. Also, for the subgroup comparisons, primarily determined as dichotomous groupings among the total sample, Cohen's $d$ was used to evaluate effect size and further assess trending relationships. Cohen's $d$ was calculated as the difference between the two subgroup means divided by the standard deviation (SD) for both subgroups (or the total sample). An effect size of 0.5 or higher was interpreted as a meaningful trend.

\section{Results}

\section{Patient Characteristics}

Of the 100 interviews, as described above, 30 were conducted with patients from the US, and 10 were conducted with patients residing in each of the seven other countries included in the study. Table 1 presents the patient-reported demographic characteristics, and Table 2 presents the patient-reported clinical characteristics, both by geographic region (the US, Europe, Brazil).

Among the 100 patients, the majority were white (85.3\%) with a mean (SD) age of 53.9 (12.1) years. Of note, mean age differed across regions, and a statistically significantly higher $(P<0.001)$ proportion of patients in Europe were white (98.2\%) vs patients in the US (60.0\%). Patients had been diagnosed for a mean (SD) of $11.6(10.7)$ years, with statistically significant regional variation $(P<0.001)$ : patients in the US had been diagnosed for a mean (SD) of 7.22 (6.3) years, while patients in Europe had been diagnosed for a mean (SD) of 14.6 (11.8) years. Most patients were educated to secondary school (51.5\%) or college/university level $(41.4 \%)$ and a statistically significantly higher $(P<0.001)$ proportion of patients in the US were educated to college/ university level (66.7\%) vs patients in Europe (33.9\%) (Table 1). Table S1 presents additional data on the patients' lifestyle and general health characteristics.

Using a scale from $0-10$, patients, on average, rated their RA-related pain at 4.8 and their RA-related fatigue at 5.0; pain was given a statistically significantly higher $(P<0.05)$ mean 
Table I Patients' Demographic Characteristics ${ }^{\mathrm{a}}$

\begin{tabular}{|c|c|c|c|c|}
\hline $\begin{array}{l}\text { Demographic } \\
\text { Characteristics }\end{array}$ & $\begin{array}{l}\text { US } \\
(n=30)\end{array}$ & $\begin{array}{l}\text { Europe } \\
(n=60)\end{array}$ & $\begin{array}{l}\text { Brazil } \\
(n=10)\end{array}$ & $\begin{array}{l}\text { Total } \\
(n=100)\end{array}$ \\
\hline \multicolumn{5}{|l|}{ Sex, n (\%) } \\
\hline Female & $23(76.7)$ & $44(73.3)$ & $8(80.0)$ & $75(75.0)$ \\
\hline Current age, mean (SD) & $52.2(10.9)$ & $55.6(12.4)$ & $48.7(12.7)$ & $53.9(12.1$ \\
\hline \multicolumn{5}{|l|}{ Race/ethnicity, ${ }^{\mathrm{b}}$ (\%) } \\
\hline White & $18(60.0)^{c}$ & $54(98.2)^{c}$ & $9(90.0)$ & $81(85.3)$ \\
\hline Black & $10(33.3)$ & $0(0.0)$ & I (10.0) & II (1I.6) \\
\hline Asian & $0(0.0)$ & $0(0.0)$ & $0(0.0)$ & $0(0.0)$ \\
\hline Hispanic & $2(6.7)$ & $0(0.0)$ & $0(0.0)$ & $2(2.1)$ \\
\hline Other & $0(0.0)$ & I (I.8) & $0(0.0)$ & $\mathrm{I}(\mathrm{I} . \mathrm{I})$ \\
\hline Prefer not to answer & $0(0.0)$ & $5(8.3)$ & $0(0.0)$ & $5(5.0)$ \\
\hline \multicolumn{5}{|l|}{ Education, ${ }^{\mathrm{b}} \mathrm{n}(\%)$} \\
\hline Primary school & $0(0.0)$ & 7 (11.9) & $0(0.0)$ & $7(7.1)$ \\
\hline Secondary school & $10(33.3)$ & $32(54.2)$ & $9(90.0)$ & $51(51.5)$ \\
\hline $\begin{array}{l}\text { College or university } \\
\text { degree }\end{array}$ & $20(66.7)^{c}$ & $20(33.9)^{c}$ & I (10.0) & $4 I(4 I .4)$ \\
\hline Prefer not to answer & $0(0.0)$ & $\mathrm{I}(\mathrm{I} .7)$ & $0(0.0)$ & I (I.0) \\
\hline \multicolumn{5}{|l|}{ Employment, n (\%) } \\
\hline Employed full-time & $13(43.3)$ & $23(38.3)$ & $3(30.0)$ & $39(39.0)$ \\
\hline Employed part-time & $4(13.3)$ & $8(13.3)$ & $0(0.0)$ & $12(12.0)$ \\
\hline Home-maker & $6(20.0)$ & $4(6.7)$ & $3(30.0)$ & $13(13.0)$ \\
\hline $\begin{array}{l}\text { Not working (disabled, } \\
\text { unable to work) }\end{array}$ & $4(13.3)$ & $6(10.0)$ & I $(10.0)$ & II (II.0) \\
\hline $\begin{array}{l}\text { Not working (not } \\
\text { disabled) }\end{array}$ & I (3.3) & $2(3.3)$ & I $(10.0)$ & $4(4.0)$ \\
\hline Retired & $2(6.7)$ & $17(28.3)$ & $2(20.0)$ & $21(21.0)$ \\
\hline Student & $0(0.0)$ & $0(0.0)$ & $0(0.0)$ & $0(0.0)$ \\
\hline \multicolumn{5}{|l|}{ Relationship status, ${ }^{\mathrm{b}} \mathrm{n}(\%)$} \\
\hline Single & $5(16.7)$ & $6(10.2)$ & I (10.0) & $12(12.1)$ \\
\hline $\begin{array}{l}\text { Cohabiting, married, } \\
\text { or civil partnership }\end{array}$ & $21(70.0)$ & $44(74.6)$ & $8(80.0)$ & $73(73.7)$ \\
\hline Other $^{d}$ & $4(13.3)$ & $9(15.3)$ & I (10.0) & $14(14.1)$ \\
\hline Prefer not to answer & $0(0.0)$ & I (I.7) & $0(0.0)$ & I (I.0) \\
\hline
\end{tabular}

Notes: ${ }^{a}$ All variables were patient-reported. ${ }^{b}$ Percentages for responses other than "Prefer not to answer" do not include any patients who endorsed "Prefer not to answer". "Statistically significant $(P<0.00 \mathrm{I})$ difference between the US and Europe.

'Separated, divorced, or widowed.

Abbreviations: $n$, number of patients; SD, standard deviation; US, United States.

(SD) score by patients in Europe (5.3 [2.7]) than by those in the US (4.0 [2.3]; Table 2). Most patients reported currently experiencing pain/ache symptoms $(90.0 \%)$. Table S2 presents additional data regarding patients' RA symptoms. Numerically higher proportions of patients in Brazil (80.0\%) and the US $(70.0 \%)$ reported that their symptoms had improved since diagnosis compared with patients from Europe (50.0\%; Table S2).

Current RA treatment modes reported by the patients included oral administration $(60.0 \%)$, self- or clinic-injection $(57.0 \%)$, and infusion (14.0\%); the majority of patients
Table 2 Patients' Clinical Characteristics ${ }^{\mathrm{a}}$

\begin{tabular}{|c|c|c|c|c|}
\hline $\begin{array}{l}\text { Clinical } \\
\text { Characteristics }\end{array}$ & $\begin{array}{l}\text { US } \\
(n=30)\end{array}$ & $\begin{array}{l}\text { Europe } \\
(n=60)\end{array}$ & $\begin{array}{l}\text { Brazil } \\
(n=10)\end{array}$ & $\begin{array}{l}\text { Total } \\
(n=100)\end{array}$ \\
\hline $\begin{array}{l}\text { Age at first symptom, } \\
\text { mean (SD) }\end{array}$ & $41.4(12.9)$ & $38.2(15.1)$ & 35.5 (11.7) & $38.9(14.1)$ \\
\hline $\begin{array}{l}\text { Diagnosed age, } \\
\text { mean (SD) }\end{array}$ & $44.6(12.4)$ & $41.0(15.0)$ & $41.6(9.8)$ & $42.2(13.8)$ \\
\hline $\begin{array}{l}\text { Years diagnosed, } \\
\text { mean (SD) }\end{array}$ & $7.2(6.3)^{\mathrm{b}}$ & $14.6(11.8)^{b}$ & $7.1(8.1)$ & $11.6(10.7)$ \\
\hline Pain NRS, ${ }^{c}$ mean (SD) & $4.0(2.3)^{d}$ & $5.3(2.7)^{\mathrm{d}}$ & $4.5(2.5)$ & $4.8(2.6)$ \\
\hline $\begin{array}{l}\text { Fatigue NRS, } \\
\text { mean (SD) }\end{array}$ & $4.5(2.7)$ & $5.4(3.0)$ & $4.1(3.1)$ & $5.0(2.9)$ \\
\hline $\begin{array}{l}\text { Severity of RA, }{ }^{\text {,ff }} \mathrm{n}(\%) \\
\text { Mild } \\
\text { Moderate } \\
\text { Severe } \\
\text { Very severe } \\
\text { Prefer not to answer }\end{array}$ & $\begin{array}{l}9(32.1) \\
14(50.0) \\
4(14.3) \\
1(3.6) \\
2(6.7)\end{array}$ & $\begin{array}{l}14(23.3) \\
24(40.0) \\
19(31.7) \\
3(5.0) \\
0(0.0)\end{array}$ & $\begin{array}{l}2(20.0) \\
7(70.0) \\
1(10.0) \\
0(0.0) \\
0(0.0)\end{array}$ & $\begin{array}{l}25(25.5) \\
45(45.9) \\
24(24.5) \\
4(4.1) \\
2(2.0)\end{array}$ \\
\hline \multicolumn{5}{|l|}{$\begin{array}{l}\text { Current symptoms, } \\
\mathrm{n}(\%)\end{array}$} \\
\hline Pain, ache & $29(96.7)$ & $51(85.0)$ & $10(100.0)$ & $90(90.0)$ \\
\hline $\begin{array}{l}\text { Swelling/ } \\
\text { inflammation }\end{array}$ & $17(56.7)$ & $35(58.3)$ & $6(60.0)$ & $58(58.0)$ \\
\hline $\begin{array}{l}\text { Loss of strength/ } \\
\text { weakness }\end{array}$ & $12(40.0)$ & $7(11.7)$ & $3(30.0)$ & $22(22.0)$ \\
\hline Stiffness & $16(53.3)$ & $26(43.3)$ & $2(20.0)$ & $44(44.0)$ \\
\hline $\begin{array}{l}\text { Function loss } \\
\text { (dexterity, mobility, } \\
\text { agility) }\end{array}$ & $21(70.0)$ & $38(63.3)$ & $8(80.0)$ & $67(67.0)$ \\
\hline Fatigue & $19(63.3)$ & $30(50.0)$ & $5(50.0)$ & $54(54.0)$ \\
\hline Numbness & $0(0.0)$ & $4(6.7)$ & $0(0.0)$ & $4(4.0)$ \\
\hline Depression & I (3.3) & $2(3.3)$ & $0(0.0)$ & $3(3.0)$ \\
\hline
\end{tabular}

Notes: ${ }^{a}$ All variables were patient-reported. ${ }^{b}$ Statistically significant $(P<0.00 \mathrm{I})$ difference between the US and Europe. 'Pain and fatigue in the 7 days prior to the interview were rated by the patients on a scale of 0 to 10 , where 0 represented no pain or fatigue and 10 represented the worst possible pain or fatigue. ${ }^{\mathrm{d} S}$ Statistically significant $(P<0.05)$ difference between the US and Europe. ${ }^{e}$ Percentages for responses other than "Prefer not to answer" do not include any patients who endorsed "Prefer not to answer". 'Patients were asked to describe the current severity of their RA as mild, moderate, severe, or very severe. ${ }^{\text {PPatients }}$ were asked what RA symptoms they were currently experiencing; multiple response item; responses sum to over $100 \%$.

Abbreviations: $\mathrm{n}$, number of patients; NRS, numeric rating scale; RA, rheumatoid arthritis; SD, standard deviation; US, United States.

reported previous or current experience of bDMARDs (70.0\%), injection (subcutaneous) medications (79.0\%), and MTX (81.0\%); a minority of patients had lifetime experience with infusion medications (37.0\%) (Table 3). The majority of patients $(96.0 \%)$ were currently receiving a csDMARD and/or bDMARD: $40.0 \%$ were receiving a csDMARD without a bDMARD, $30.0 \%$ were receiving a csDMARD with a bDMARD, and $26.0 \%$ were receiving a bDMARD without a csDMARD (Table 3). 
Table 3 Patients' Medication Experience

\begin{tabular}{|c|c|c|c|c|}
\hline & US $(n=30)$ & Europe $(n=60)$ & Brazil $(n=10)$ & Total $(n=100)$ \\
\hline \multicolumn{5}{|l|}{ Current RA Medication, ${ }^{\mathbf{a}}$ n (\%) } \\
\hline csDMARD and/or bDMARD & $27(90.0)$ & $59(98.3)$ & $10(100.0)$ & $96(96.0)$ \\
\hline csDMARD monotherapy (no bDMARD) & $12(40.0)$ & $23(38.3)$ & $5(50.0)$ & $40(40.0)$ \\
\hline csDMARD + bDMARD combination therapy & $8(26.7)$ & $20(33.3)$ & $2(20.0)$ & $30(30.0)$ \\
\hline bDMARD monotherapy (no csDMARD) & $7(23.3)$ & $16(26.7)$ & $3(30.0)$ & $26(26.0)$ \\
\hline Steroid & $5(16.7)$ & II (I8.3) & $2(20.0)$ & $18(18.0)$ \\
\hline tsDMARD & $4(13.3)$ & $0(0.0)$ & $0(0.0)$ & $4(4.0)$ \\
\hline Methotrexate ${ }^{b}$ & $12(40.0)$ & $38(63.3)$ & $7(70.0)$ & $57(57.0)$ \\
\hline \multicolumn{5}{|l|}{ Current RA Medication Mode, ${ }^{c}$ n (\%) } \\
\hline Oral & $21(70.0)$ & $32(53.3)$ & $7(70.0)$ & $60(60.0)$ \\
\hline Injection & $15(50.0)$ & $40(66.7)$ & $2(20.0)$ & $57(57.0)$ \\
\hline Infusion & $2(6.7)$ & $9(15.0)$ & $3(30.0)$ & $14(14.0)$ \\
\hline \multicolumn{5}{|l|}{ Lifetime Experience (Yes), ${ }^{\mathrm{d}}$ n (\%) } \\
\hline bDMARD & $21(70.0)$ & $43(71.7)$ & $6(60.0)$ & $70(70.0)$ \\
\hline Injection & $24(80.0)$ & $5 \mathrm{I}(85.0)$ & $4(40.0)$ & $79(79.0)$ \\
\hline Methotrexate & $21(70.0)$ & $53(88.3)$ & $7(70.0)$ & $81(81.0)$ \\
\hline Infusion & $9(30.0)$ & $22(36.7)$ & $6(60.0)$ & $37(37.0)$ \\
\hline
\end{tabular}

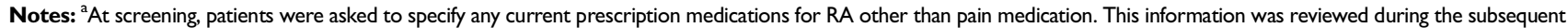
study interview. ${ }^{\text {} A l s o ~ c o u n t e d ~ i n ~ c s D M A R D ~ r o w s . ~ ' P a t i e n t s ~ w e r e ~ a s k e d ~ w h e t h e r ~ c u r r e n t ~ R A ~ m e d i c a t i o n s ~ w e r e ~ t a k e n ~ o r a l l y ~(t a b l e t ~ o r ~ p i l l), ~ b y ~ i n j e c t i o n ~(s e l f-i n j e c t e d ~ a t ~ h o m e ~ o r ~ a t ~}$

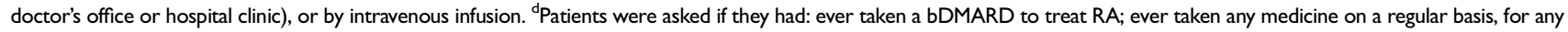
condition, that required injection; ever taken methotrexate to treat RA; and ever taken any medicine on a regular basis, for any condition, that required infusion.

Abbreviations: bDMARD, biologic DMARD; csDMARD, conventional synthetic DMARD; DMARD, disease-modifying antirheumatic drug; $n$, number of patients; RA, rheumatoid arthritis; tsDMARD, targeted synthetic DMARD; US, United States.

\section{Treatment Mode Preferences}

Among the four treatment modes, across which each patient allocated 100 points to indicate their preferred mode, on average, the oral and self-injection modes received most points and were most commonly chosen as patients' first-choice mode (ie, the mode with the most points allocated; Figure 1A and B). Across all patients, oral administration received a mean (SD) point allocation of 47.3 (33.1) and was the first-choice mode for $57.0 \%$ of patients. Self-injection was allocated 29.7 (27.7) points and was the first choice for $29.0 \%$ of patients, followed by infusion (15.4 [24.6] points, first choice for $16.0 \%$ of patients), and clinic-injection (7.5 [14.1] points, first choice for $2.0 \%$ of patients).

Across all patients and treatment modes, $56.0 \%$ of patients had a "strong" first-choice preference (ie, a point allocation of $\geq 70$, which was the median number of points allocated across the first-ranked choices; Figure 2A). Among patients with a "strong" preference, the majority chose oral administration (62.5\%) followed by self-injection (23.2\%), infusion (10.7\%), and clinic-injection (3.6\%; Figure 2B).

\section{Reasons for Treatment Mode Preferences}

Figure 3 presents the most common ( $\geq 25 \%$ of patients) reasons provided by patients in support of their first-choice preference and the reasons they did not prefer or give more preference points to modes other than their first choice. Illustrative patient quotations for these reasons are listed in

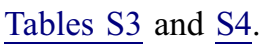

Patients who chose oral as their preferred mode of treatment administration commonly cited speed $(52.6 \%)$ and ease $(52.6 \%)$ of administration as reasons for their choice. Patients who chose self-injection as their preferred mode also cited speed of administration $(55.2 \%)$ as a reason for their preference. Most patients who preferred infusion valued less-frequent dosing intervals $(81.3 \%)$. Only two patients chose clinicinjection as their preferred mode, with reasons including a preference for someone else administering the injection (Figure 3).

Patients who did not prefer the oral mode commonly cited a reluctance to take another pill (37.2\%). Among patients who did not prefer the self-injection mode, many cited a desire to avoid pain associated with needles (46.5\%), or to avoid needles altogether (42.3\%). Nearly all patients (98 of 100) did not prefer the clinic-injection mode, most commonly citing the inconvenience of clinic visits (70.4\%). Similarly, patients who did not prefer the infusion mode commonly considered it inconvenient (66.7\%; Figure 3). 
A

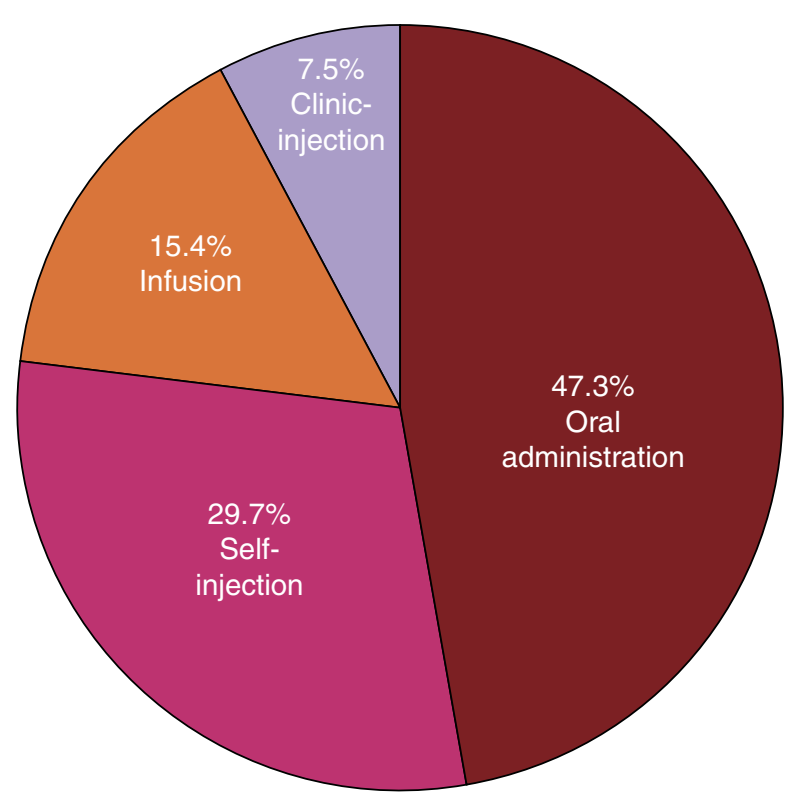

B

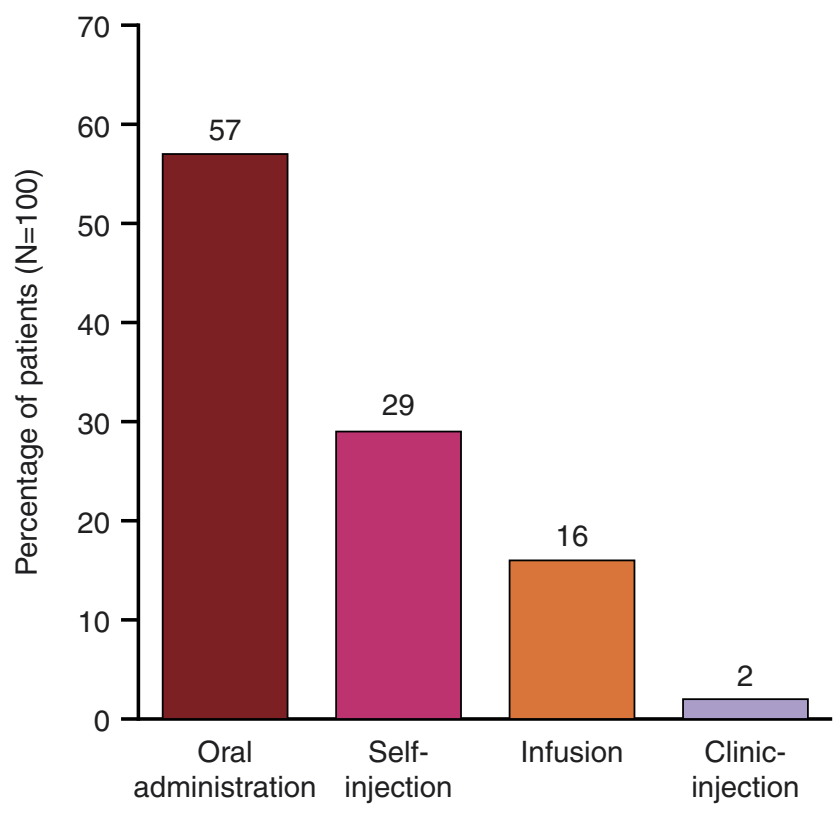

First choice

Figure I (A) 100-point allocation ${ }^{\mathrm{a}}$ means and (B) first-choice treatment mode preference ${ }^{\mathrm{b}}(\mathrm{N}=100)$

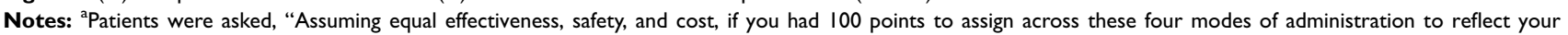
preferences, how would you allocate these points?". 'A patient's first-choice mode was the mode with the most points allocated; percentages sum to I04\% because four patients provided ties for their first-choice mode; these tied modes were counted twice in the percentages (oral and self-injection [ $\mathrm{n}=3$ ]; oral and infusion [ $\mathrm{n}=\mathrm{I}]$ ).

A

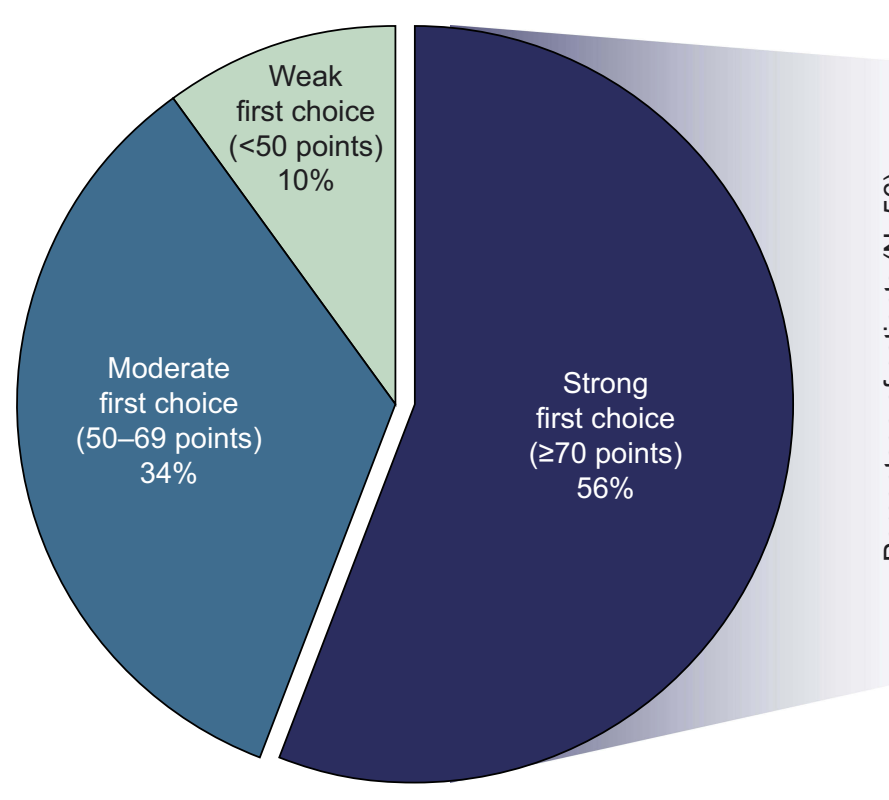

B

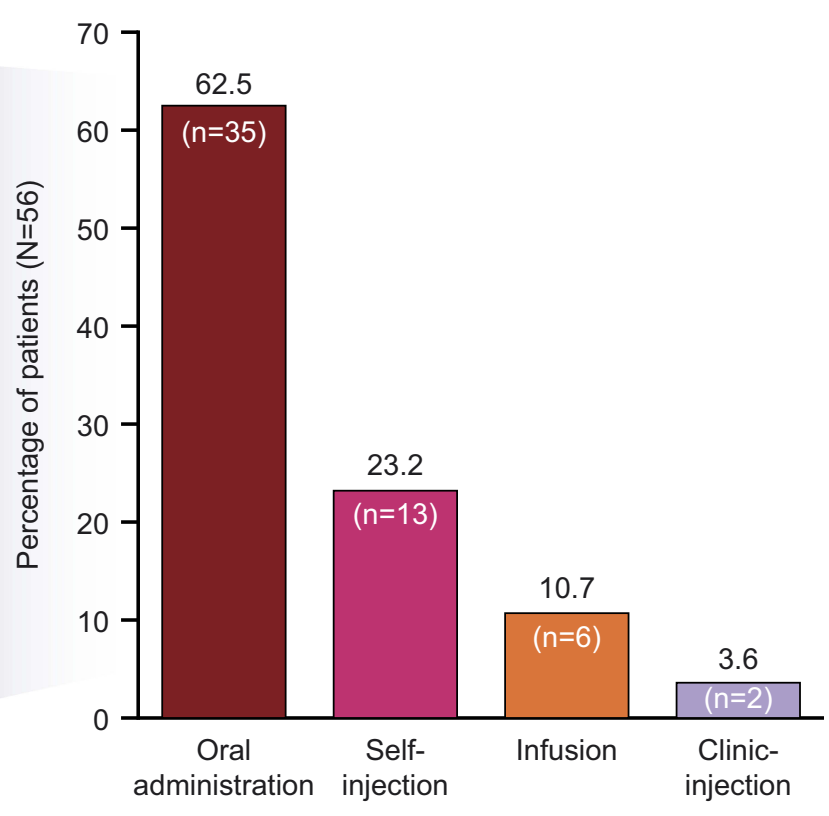

Strong first choice

Figure 2 (A) Strength of first choices $(\mathrm{N}=100)$ and $(B)$ mode preferences among strong first choices $(\mathrm{N}=56)$. 


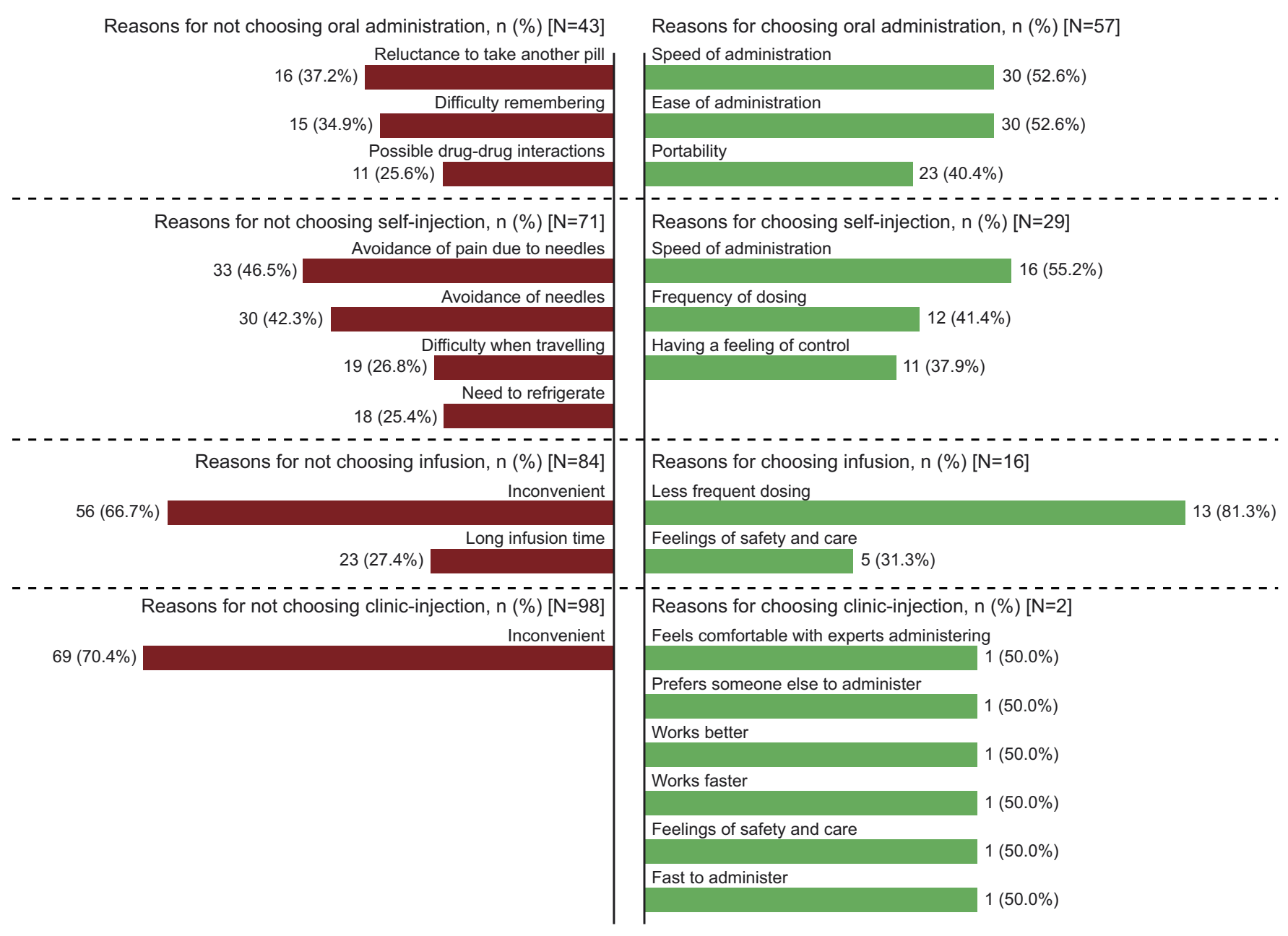

Figure 3 Most common $^{\mathrm{a}}$ reasons ${ }^{\mathrm{b}}$ for choosing and not choosing oral administration, self-injection, infusion, and clinic-injection as the most-preferred mode. Illustrative patient quotations for these reasons are listed in Tables S3 and S4.

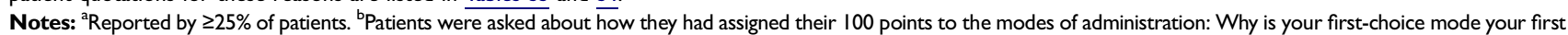
choice? Why is that important to you? What else makes it your first choice? Why is your second/third/fourth choice so far/close in preference to your first/second/third choice? What do you like about your second/third/fourth-choice mode? What do you dislike about your second/third/fourth-choice mode? What else, if anything, is related to your first-choice mode being your most preferred way to take your RA treatment? Do you think that your past experiences with treatments for RA or treatments for any other conditions affect your preference for your first-choice mode? Like what?

Abbreviations: $n$, number of patients giving reason; $N$, number of patients choosing that mode; RA, rheumatoid arthritis.

While $17.1 \%$ of the 35 patients with a strong oral mode firstchoice preference said they disliked that it was hard to remember to take pills every day, $53.8 \%$ of the 13 patients with a strong self-injection first-choice preference also cited this as a reason for disliking the oral mode (Figure 2B; Table S5). While none of the patients with a strong self-injection first-choice preference cited avoidance of needles as a reason for disliking the selfinjection mode, $51.4 \%$ of the patients with a strong oral mode first-choice preference cited this reason (Table S5).

Although many patients would consider either or both the oral and self-injection mode of administration, some patients reported avoiding these modes. Notably, three patients did not choose oral or self-injection as their first or second choice. There were 14 patients who did not choose the oral mode as their first or second choice. Their reasons are shown in Table 4, with main concerns relating to possible drug interactions $(\mathrm{n}=7 ; 50.0 \%)$ and difficulties remembering to take the pills $(\mathrm{n}=5 ; 35.7 \%)$. There were also 14 patients who did not choose self-injection as their first or second choice. Their reasons are shown in Table 4, with 78.6\% $(n=11)$ reporting one or more reasons related to the selfinjection needle and associated pain.

\section{Subgroup Analyses}

In the regional analyses, the mean points allocated to oral administration were greater in the US (mean [SD], 56.3 [27.6] points) than in Europe (mean [SD], 43.2 [32.0]) and individual countries (in which mean [SD] point allocations ranged from 30.4 [24.1] in Switzerland to 53.5 [32.7] in Spain), but the only statistically significant result was for Switzerland vs the US 
Table 4 Dislikes for Oral Mode by Patients Avoiding Oral Mode and Dislikes for Self-Injection Mode by Patients Avoiding Self-Injection Mode

\begin{tabular}{|c|c|}
\hline Oral Dislikes & $\begin{array}{l}\text { Patients Who Did Not Choose Oral as a First- or Second-Choice Mode } \\
(n=14), n(\%)\end{array}$ \\
\hline Possible interactions with other pills (in stomach) & $7(50.0)$ \\
\hline Hard to remember (Ix day; $2 x$ day) & $5(35.7)$ \\
\hline Hard to swallow pills & $3(21.4)$ \\
\hline Have to take with food & $3(21.4)$ \\
\hline Want to reduce pills & $3(21.4)$ \\
\hline Have to carry pills & I (7.I) \\
\hline Makes me feel like a sick person & I (7.I) \\
\hline Self-Injection Dislikes & $\begin{array}{l}\text { Patients Who Did Not Choose Self-Injection as a First- or Second-Choice Mode } \\
(n=14), n(\%)\end{array}$ \\
\hline Avoid needles/sticking self with needle & $7(50.0)$ \\
\hline Avoid pain, needle-stick/injection site & $6(42.9)$ \\
\hline Have to get psyched up to stick self (dread it) & $3(21.4)$ \\
\hline $\begin{array}{l}\text { Difficulties travelling (refrigeration, } \\
\text { preparation, disposal) }\end{array}$ & $3(21.4)$ \\
\hline Hard to handle/manipulate with hands & $3(21.4)$ \\
\hline Avoid pain (burning sensation) & $2(14.3)$ \\
\hline Want someone else to do it & $2(14.3)$ \\
\hline Have to refrigerate, monitor temperature & $2(14.3)$ \\
\hline Avoid preparation and disposal of syringe/injector & I (7.I) \\
\hline Hard to remember to take once per week & I (7.I) \\
\hline Makes me feel like a sick person & I (7.I) \\
\hline Frequency of dosing & I (7.I) \\
\hline
\end{tabular}

Abbreviation: $n$, number of patients.

Table 5 100-Point Allocation and First-Choice Treatment Mode Preferences by Country

\begin{tabular}{|c|c|c|c|c|c|c|c|c|c|}
\hline & $\begin{array}{l}\text { US } \\
(n=30)\end{array}$ & $\begin{array}{l}\text { France } \\
(n=10)\end{array}$ & $\begin{array}{l}\text { Germany } \\
(n=10)\end{array}$ & $\begin{array}{l}\text { Italy } \\
(n=10)\end{array}$ & $\begin{array}{l}\text { Spain } \\
(n=10)\end{array}$ & $\begin{array}{l}\text { Switzerland } \\
(n=10)\end{array}$ & $\begin{array}{l}\text { UK } \\
(n=10)\end{array}$ & $\begin{array}{l}\text { Brazil } \\
(n=10)\end{array}$ & $\begin{array}{l}\text { Total } \\
(n=100)\end{array}$ \\
\hline \multicolumn{10}{|c|}{ 100-Point Allocation Points, mean (SD) } \\
\hline Oral & $56.3(27.6)$ & $43.5(31.5)$ & $43.5(29.3)$ & $40.0(35.3)$ & $53.5(32.7)$ & $30.4(24.1)$ & $48.0(40.5)$ & 45.0 (49.7) & $47.3(33.1)$ \\
\hline Self-injection & $29.9(26.4)$ & $43.0(29.8)$ & $33.5(25.2)$ & $34.0(29.1)$ & $20.5(20.1)$ & 38.6 (23.9) & $38.0(37.4)$ & $0.0(0.0)$ & $29.7(27.7)$ \\
\hline Clinic-injection & $4.3(6.5)$ & $3.5(7.5)$ & $5.0(5.8)$ & $8.0(9.5)$ & $9.3(9.4)$ & $\mid 8.5(2 \mid .5)$ & $6.0(10.7)$ & $12.0(31.6)$ & $7.5(14.1)$ \\
\hline Infusion & $9.5(14.1)$ & $9.5(20.9)$ & $18.0(20.8)$ & $18.0(23.6)$ & $16.7(27.4)$ & $12.5(11.6)$ & $8.0(19.3)$ & $43.0(47.6)$ & I5.4 (24.6) \\
\hline \multicolumn{10}{|c|}{ First Choice, ${ }^{a}$ n (\%) } \\
\hline Oral & $22(73.3)$ & $5(50.0)$ & $6(60.0)$ & $5(50.0)$ & $5(50.0)$ & $4(40.0)$ & $5(50.0)$ & $5(50.0)$ & $57(57.0)$ \\
\hline Self-injection & $8(26.7)$ & $3(30.0)$ & $2(20.0)$ & $3(30.0)$ & $3(30.0)$ & $6(60.0)$ & $4(40.0)$ & $0(0.0)$ & $29(29.0)$ \\
\hline Clinic-injection & $0(0.0)$ & $0(0.0)$ & $0(0.0)$ & $0(0.0)$ & $0(0.0)$ & I (I0.0) & $0(0.0)$ & I (I0.0) & $2(2.0)$ \\
\hline Infusion & $2(6.7)$ & $2(20.0)$ & $2(20.0)$ & $2(20.0)$ & $2(20.0)$ & $0(0.0)$ & I $(10.0)$ & $5(50.0)$ & $16(16.0)$ \\
\hline
\end{tabular}

Notes: a Percentages sum to $>100$ because four patients provided ties for their first-choice mode; these tied modes were counted twice in the percentages (oral and selfinjection $[n=3]$; oral and infusion $[n=1]$ ).

Abbreviations: $n$, number of patients; UK, United Kingdom; US, United States.

$(P<0.05$; Table 5). When comparing the proportion of patients who chose oral administration as their first choice, a greater proportion of patients in the US chose oral administration than in Europe $(P<0.05$; Table 6$)$; no other between-country differences were statistically significant.
No statistically significant differences in preferences (means or proportions) were observed for the other sociodemographic factors (eg, employment status, race/ethnicity), clinical factors (eg, years since RA diagnosis, current RA pain severity, or overall severity), and lifestyle factors (eg, 
Table 6 First- and Second-Choice Treatment Mode Preferences by Country Group

\begin{tabular}{|c|c|c|c|}
\hline & US $(n=30)$ & Europe $(n=60)$ & Total $(n=100)^{a}$ \\
\hline \multicolumn{4}{|c|}{ First Choice, ${ }^{\mathrm{b}}$ n (\%) } \\
\hline Oral & $22(73.3)^{c}$ & $30(50.0)^{c}$ & $57(57.0)$ \\
\hline Self-injection & $8(26.7)$ & $21(35.0)$ & $29(29.0)$ \\
\hline Clinic-injection & $0(0.0)$ & I (I.7) & $2(2.0)$ \\
\hline Infusion & $2(6.7)$ & $9(15.0)$ & $16(16.0)$ \\
\hline \multicolumn{4}{|c|}{ Second Choice, ${ }^{\mathrm{d}} \mathrm{n}(\%)$} \\
\hline Oral & $9(30.0)$ & $19(31.7)$ & $33(33.0)$ \\
\hline Self-injection & $19(63.3)$ & $33(55.0)$ & $60(60.0)$ \\
\hline Clinic-injection & $6(20.0)$ & $20(3.3)$ & $34(34.0)$ \\
\hline Infusion & $9(30.0)$ & $17(28.3)$ & $32(32.0)$ \\
\hline
\end{tabular}

Notes: ${ }^{a}$ Includes Brazil, $n=10$. ${ }^{b}$ Percentages sum to $>100$ because four patients provided ties for their first-choice mode; these tied modes were counted twice in the percentages (oral and self-injection [ $n=3$ ]; oral and infusion $[n=I]$ ). ${ }^{C} P<0.05$ between the US and Europe. 'Percentages sum to $>100$ because 36 patients provided ties for their second-choice mode: 21 patients provided three-way ties for their second-choice mode because their firstchoice mode was given 100 points (thus second, third, and fourth choice were all allocated 0 points); two patients provided three-way ties where their first-choice mode was not given 100 points; 13 patients provided two-way ties; two-way tied modes were counted twice in the percentages and three-way tied modes were counted three times in the percentages. Abbreviations: n, number of patients; US, United States.

alcohol consumption, exercise habits). Patients currently treated with infusion were significantly more likely to prefer the infusion mode $(42.9 \%$ vs $11.6 \%$ for infusion users vs non-users; $P<0.01)$ and gave more preference points to the infusion mode (37.1 vs 11.9 for infusion users vs non-users; $P<0.001)$ than patients without current infusion experience. While not statistically significant, all other first-choice percentages and point allocations were higher for any given mode among current users vs current non-users: $60.0 \%$ vs $52.5 \%$ and 52.2 vs 39.9 points for oral administration; $35.1 \%$ vs $20.9 \%$ and 35.5 vs 22.0 points for self-injection; $3.5 \%$ vs $0.0 \%$ and 9.4 vs 5.0 points for clinic-injection. Because no significant differences (except for infusion experience) were observed in the subgroup comparisons, trends between each grouping were evaluated (Table S6).

\section{Treatment Mode Scenarios}

Of the patients who preferred the oral mode, when asked for their opinion on taking their medication twice daily rather than once daily, nearly two-thirds of patients said it would not make a difference, while approximately onequarter of patients expressed some concerns, often related to the increased likelihood of forgetting to take a dose. Only a few patients said that they would consider switching to another mode of administration in this situation, because of concerns regarding difficulties remembering and the increased levels of medication in their bodies. Adding a second drug to their oral treatment was not enough for the majority of patients to switch their preference for oral to another mode.

Among the patients who were open to the self-injection mode, around half were neutral and the other half were generally receptive to the possibility that self-injection would be required every 2 weeks instead of every week. Some of these patients were not interested in the decreased frequency, either noting that it did not make a difference to them or the possibility that every 2 weeks would be harder to remember; others commented that having injections every 2 weeks was a clear advantage.

Among patients asked about their perceptions of MTX, more than half reported negative feelings. The negative beliefs focused mainly on the drug side effects and safety, with some of these based on personal experiences of the drug, while others based their concerns on indirect experience and knowledge. Some patients expressed concerns about being unable to consume alcohol while taking MTX. When asked about bDMARDs, few patients expressed negative perceptions.

\section{Discussion}

This multi-national, cross-sectional qualitative study explored in-depth each patient's beliefs and perceptions related to RA treatment modes. More than half of patients (57\%) ranked oral administration as their preferred mode of RA treatment, followed by self-injection, infusion, and clinic-injection, which were preferred by $29 \%, 16 \%$, and $2 \%$ of patients, respectively. While previous studies of patients with RA in the US and Europe have similarly found oral administration to be preferred over injection or infusion, ${ }^{10,16,17}$ the reasons for these preferences have not previously been studied in-depth.

In this study, the most frequently reported reasons for preferring the oral mode were speed and ease of administration, and portability. Reasons for choosing self-injection also included the speed of administration, but patients also liked the less-frequent dosing (every week) and sense of control associated with self-injection. While fewer patients preferred infusions, these patients valued the less-frequent dosing, as well as the care, comfort, and stress-free environment they perceived at the time of their treatments.

Although more than half of patients had a strong first choice, $44 \%$ of patients did not, highlighting that for many patients there may be an opportunity for discussions with their healthcare professional and/or patient support groups about RA treatment mode options, to inform their 
treatment choices. Such discussions must always occur in the context of appropriate consideration of the optimal benefit-risk profile of any given therapy for an individual based upon a thorough assessment of disease status and any associated comorbidities.

Interestingly, a significantly higher proportion $(P<0.05)$ of patients in the US chose oral administration as their first choice compared to patients in Europe. A previous surveybased study within Europe has also shown preferred modes to differ by country. ${ }^{15}$ Since geographic and cultural differences may affect patients' preference of treatment mode, this should be considered when making treatment decisions.

Subgroup analyses revealed that patients with infusion experience were significantly more likely to prefer infusion than patients without such experience. This is unsurprising since we are conditioned by our prior experiences, and change can feel risky to a patient who is familiar with a certain treatment mode and who feels that mode is part of the solution to their disease. This is a factor to be considered when a physician recommends a treatment change when other choices are available.

No significant differences were found among other subgroup pairs dichotomized by sociodemographic, clinical, or lifestyle characteristics or among country samples. In comparison, a discrete-choice experiment study of 733 Canadian patients found that those with no experience of injectable treatments had preferences for oral administration relative to infusion, whereas those with experience of injectable treatments did not have any significant preferences for one treatment mode over another. ${ }^{14}$ The absence of statistically significant differences between dichotomized subgroups due to small sample size in the current study should be explored in future research.

Some limitations of this study, primarily related to its qualitative design and small sample size, must be noted. While this study elicited in-depth information about each patient's beliefs and perceptions related to RA treatment modes, its qualitative design and relatively small sample size preclude direct comparisons to be made between countries or subgroups with any level of confidence and limit the ability to generalize the results in the wider RA population. Some demographic and disease characteristics differed across groups, including current age and age at first symptom, as well as disease progression since diagnosis. However, interpretation of any differences between countries or between subgroups is speculative. Additionally, comparisons are limited to the eight countries included in the study and the demographic groups represented by the recruited patients. Notably, the sample included no patients of Asian race/ethnicity. Furthermore, not all patients had experience with all four RA treatment modes; it would be difficult for patients to provide their opinion on treatment modes that they had not experienced.

Nonetheless, findings from this study help raise awareness of issues beyond clinical features of RA treatments such as safety and efficacy that may be important to patients with RA. The patient viewpoint is a significant factor in shared decision-making for physicians and patients choosing RA treatment options. The results from this study can be used to enhance the current understanding related to patients' RA treatment mode preferences and the reasons for these preferences, and to generate specific hypotheses to be tested in future, larger-scaled studies.

\section{Conclusion}

The data reported here describe patient preferences towards various modes of administration of RA treatment, and provide in-depth information regarding the associated individual perceptions behind these preferences, illustrating the role of cultural and environment influences on patient perceptions and preferences.

\section{Abbreviations}

bDMARD, biologic DMARD; csDMARD, conventional synthetic DMARD; DMARD, disease-modifying antirheumatic drug; GP, general practitioner; MTX, methotrexate; NRS, numeric rating scale; RA, rheumatoid arthritis; SD, standard deviation; tsDMARD, targeted synthetic DMARD; UK, United Kingdom; US, United States.

\section{Ethics Approval and Informed Consent}

All patients provided written informed consent, and the RTI International Institutional Review Board reviewed the study on ethical grounds in the US. In the European countries and Brazil, the study was exempt from ethics committee review in accordance with national criteria.

\section{Acknowledgments}

Medical writing support, under the guidance of the authors, was provided by Kate Lothman, BA, of RTI Health Solutions, and Sarah Piggott, MChem, of CMC 
Connect, a division of McCann Health Medical Communications Ltd, Glasgow, UK and was funded by Pfizer Inc, New York, NY, USA in accordance with Good Publication Practice (GPP3) guidelines (Ann Intern Med 2015;163:461-464).

\section{Author Contributions}

PCT, NB, TMB, JW, DW, CC, DPdL, and LF contributed to the study conception and design. TMB, DW, and OO-A contributed to the acquisition of data. All authors contributed to the analysis and interpretation of data, drafted the article or revised it critically for important intellectual content, gave final approval of the version of the article to be published, and agree to be accountable for all aspects of the work.

\section{Funding}

This study was performed under a research contract between RTI Health Solutions and Pfizer Inc, and was funded by Pfizer Inc.

\section{Disclosure}

PCT has received research grants from Eli Lilly, Galapagos, and UCB; and is a consultant for AbbVie, Eli Lilly, Galapagos, Gilead, and Pfizer Inc. NB is a consultant for Amgen, Eli Lilly, Grunenthal, Pfizer Inc, Roche, and Sanofi; reports personal fees from GSK and from Global Alliance for Patient Access, and is International Liaison Officer for EULAR. TMB, DW, and OO-A are employees of RTI Health Solutions, who were paid consultants to Pfizer Inc in connection with the development of this manuscript. JW, CC, PD, DPdL, DG, and LF are employees and shareholders of Pfizer Inc. AJK is a shareholder of Novartis; a consultant for AbbVie, Boehringer Ingelheim, Flexion, Genzyme, Janssen, Pfizer Inc, Regeneron, Sanofi, SUN Pharma, and UCB; a member of speakers' bureaus for Celgene, Flexion, Genentech, Genzyme, Horizon, Ironwood, Merck, Novartis, Pfizer Inc, Regeneron, and Sanofi; and President of Altoona Center for Clinical Research. He also reports personal fees from Amgen, personal fees from Gilead, personal fees from GSK, outside the submitted work. CZ has received research grants from Amgen, Biogen, Eli Lilly, Merck, Novartis, Pfizer Inc, and Sanofi; and is a member of speakers' bureaus for Amgen, Eli Lilly, Pfizer Inc, and Sanofi. The authors report no other conflicts of interest in this work.

\section{References}

1. Scott DL, Wolfe F, Huizinga TW. Rheumatoid arthritis. Lancet. 2010;376(9746):1094-1108. doi:10.1016/S0140-6736(10)60826-4

2. Cross M, Smith E, Hoy D, et al. The global burden of rheumatoid arthritis: estimates from the global burden of disease 2010 study. Ann Rheum Dis. 2014;73(7):1316-1322. doi:10.1136/annrheumdis-2013-204627

3. Aletaha D, Neogi T, Silman AJ, et al. 2010 Rheumatoid arthritis classification criteria: an American College of Rheumatology/ European League Against Rheumatism collaborative initiative. Arthritis Rheum. 2010;62(9):2569-2581. doi:10.1002/art.27584

4. Scott IC, Machin A, Mallen CD, Hider SL. The extra-articular impacts of rheumatoid arthritis: moving towards holistic care. $B M C$ Rheumatol. 2018;2:32. doi:10.1186/s41927-018-0039-2

5. Singh JA, Saag KG, Bridges SL Jr, et al. 2015 American College of Rheumatology guideline for the treatment of rheumatoid arthritis. Arthritis Rheumatol. 2016;68(1):1-26. doi:10.1002/art.39480

6. Smolen JS, Landewé R, Bijlsma J, et al. EULAR recommendations for the management of rheumatoid arthritis with synthetic and biological disease-modifying antirheumatic drugs: 2016 update. Ann Rheum Dis. 2017;76(6):960-977. doi:10.1136/annrheumdis-2016-210715

7. Goodman SM, Cronstein BN, Bykerk VP. Outcomes related to methotrexate dose and route of administration in patients with rheumatoid arthritis: a systematic literature review. Clin Exp Rheumatol. 2015;33 (2):272-278.

8. Australian Rheumatology Association. Things to consider when taking a biologic; 2017. Available from: https://arthritisaustralia.com.au/ wordpress/wp-content/uploads/2018/01/Things-To-ConsiderBiologic_PDF-final_180124.pdf. Accessed March 15, 2019.

9. Gibofsky A, Galloway J, Kekow J, et al. Comparison of patient and physician perspectives in the management of rheumatoid arthritis: results from global physician- and patient-based surveys. Health Qual Life Outcomes. 2018;16(1):211. doi:10.1186/s12955-018-1035-3

10. Zhu B, Chang L, Qian L, Larmore CJ, Tanaka Y, Araujo AB. RA medication preferences among U.S. patients in an online rheumatoid arthritis community. Arthritis Rheumatol. 2016;68 Suppl 10:2238.

11. Fraenkel L, Bogardus ST, Concato J, Felson DT, Wittink DR. Patient preferences for treatment of rheumatoid arthritis. Ann Rheum Dis. 2004;63(11):1372-1378. doi:10.1136/ard.2003.019422

12. Louder AM, Singh A, Saverno K, et al. Patient preferences regarding rheumatoid arthritis therapies: a conjoint analysis. Am Health Drug Benefits. 2016;9(2):84-93.

13. Augustovski F, Beratarrechea A, Irazola V, et al. Patient preferences for biologic agents in rheumatoid arthritis: a discrete-choice experiment. Value Health. 2013;16(2):385-393. doi:10.1016/j.jval.2012.11.007

14. Harrison M, Marra C, Shojania K, Bansback N. Societal preferences for rheumatoid arthritis treatments: evidence from a discrete choice experiment. Rheumatology (Oxford). 2015;54(10):1816-1825. doi:10.1093/rheumatology/kev113

15. Barclay N, Tarallo M, Hendrikx T, Marett S. Patient preference for oral versus injectable and intravenous methods of treatment for rheumatoid arthritis. At: 16th Annual European Congress of the International Society of Pharmacoeconomics and Outcomes Research (ISPOR-EU); November 2-6; 2013; Dublin, Ireland.

16. Taylor PC, Rieke A, Gomez-Reino JJ, et al. Mode of administration in rheumatoid arthritis treatments: an exploration of patient preference for an 'ideal treatment'. Arthritis Rheumatol. 2016;68 Suppl 10:2492.

17. Alten R, Krüger K, Rellecke J, et al. Examining patient preferences in the treatment of rheumatoid arthritis using a discrete-choice approach. Patient Prefer Adherence. 2016;10:2217-2228. doi:10.2147/PPA.S117774

18. Kumar K, Klocke R. Ethnicity in rheumatic disease. Clin Med (Lond). 2010;10(4):370-372. doi:10.7861/clinmedicine.10-4-370

19. Barton JL, Trupin L, Schillinger D, et al. Racial and ethnic disparities in disease activity and function among persons with rheumatoid arthritis from university-affiliated clinics. Arthritis Care Res (Hoboken). 2011;63(9):1238-1246. doi:10.1002/acr.20525 
20. Greenberg JD, Spruill TM, Shan Y, et al. Racial and ethnic disparities in disease activity in patients with rheumatoid arthritis. $\mathrm{Am} \mathrm{J} \mathrm{Med}$. 2013;126(12):1089-1098. doi:10.1016/j.amjmed.2013.09.002

21. Bruce B, Fries JF, Murtagh KN. Health status disparities in ethnic minority patients with rheumatoid arthritis: a cross-sectional study J Rheumatol. 2007;34(7):1475-1479.

22. Yazici Y, Kautiainen H, Sokka T. Differences in clinical status measures in different ethnic/racial groups with early rheumatoid arthritis: implications for interpretation of clinical trial data. $J$ Rheumatol. 2007;34(2):311-315.
23. Tan BE, Lim AL, Kan SL, et al. Management of rheumatoid arthritis in clinical practice using treat-to-target strategy: where do we stand in the multi-ethnic Malaysia population? Rheumatol Int. 2017;37 (6):905-913. doi:10.1007/s00296-017-3705-6

24. Braun V, Clarke V. Using thematic analysis in psychology. Qual Res Psychol. 2006;3(2):77-101. doi:10.1191/1478088706qp063oa

25. SAS Proprietary Software, Version 9.4 [Computer Program]. Cary, NC: SAS Institute Inc.
Patient Preference and Adherence

\section{Publish your work in this journal}

Patient Preference and Adherence is an international, peer-reviewed, open access journal that focusing on the growing importance of patient preference and adherence throughout the therapeutic continuum. Patient satisfaction, acceptability, quality of life, compliance, persistence and their role in developing new therapeutic modalities and compounds to optimize clinical outcomes for existing disease

\section{Dovepress}

states are major areas of interest for the journal. This journal has been accepted for indexing on PubMed Central. The manuscript management system is completely online and includes a very quick and fair peer-review system, which is all easy to use. Visit http:// www.dovepress.com/testimonials.php to read real quotes from published authors. 